\title{
A Psicologia e a Educação Moral
}

Psychology and Moral Education

Leonardo Rodrigues

Sampaio

Universidade Federal do Vale do São Francisco

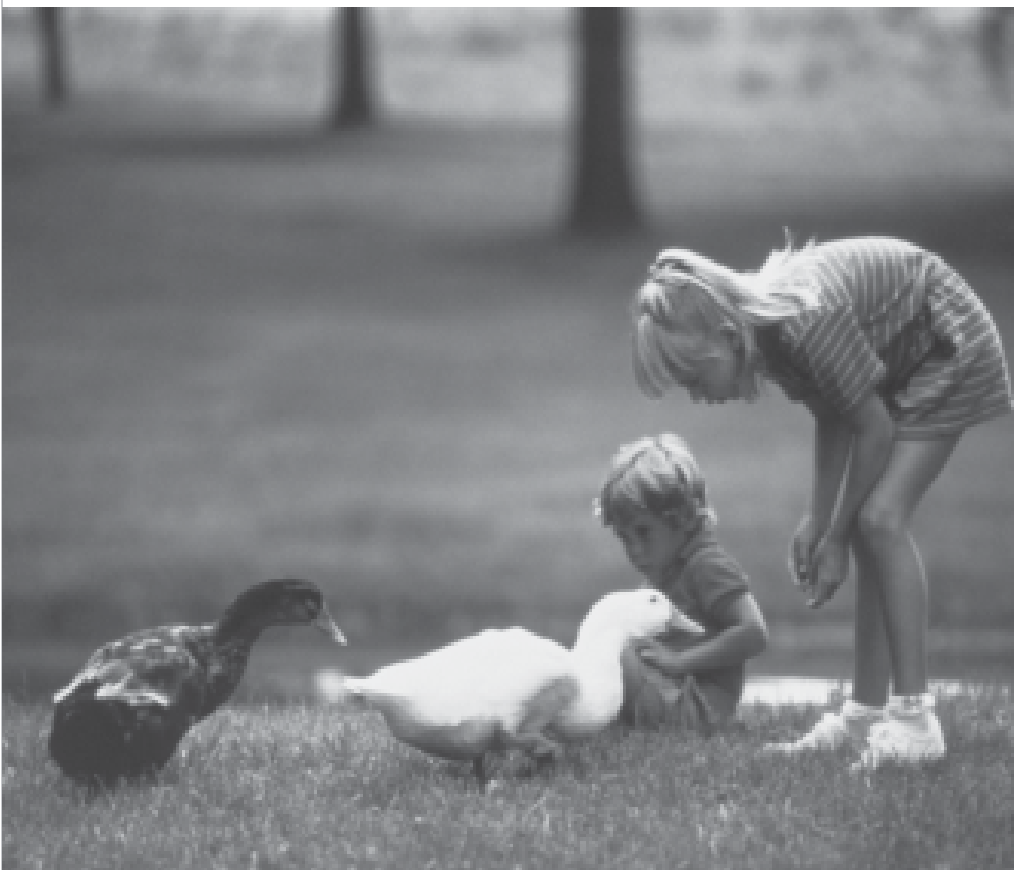




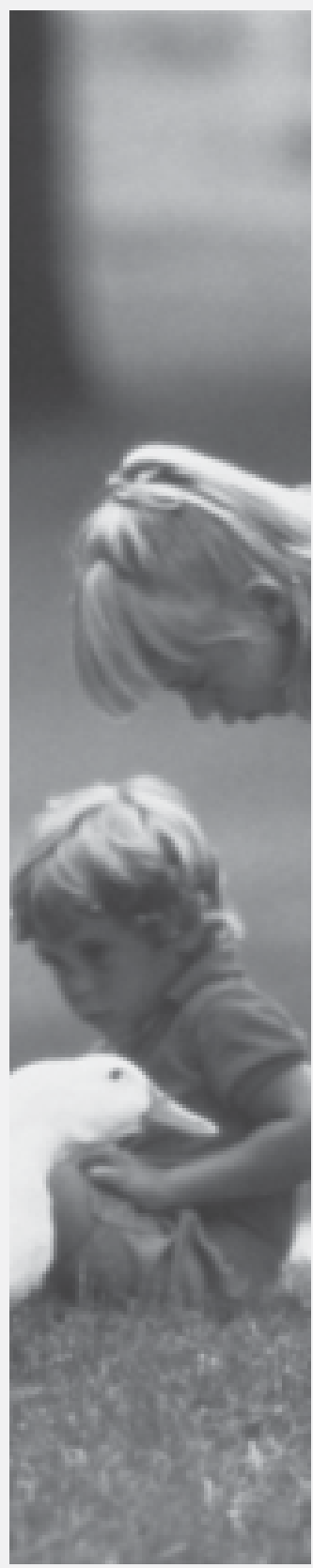

Resumo: Na Psicologia, o campo de estudos sobre o desenvolvimento moral, a partir de uma perspectiva psicogenética, teve início com o trabalho O Juízo Moral na Criança, escrito por Jean Piaget, em 1932. Nesse livro, o psicólogo suíço relata uma série de experimentos que demonstram que a moralidade se desenvolve com o passar do tempo e à medida que novas aquisições no campo cognitivo e afetivo são conquistadas pelo sujeito. De lá para cá, esse campo de estudos tem crescido constantemente e produzido novas teorias e propostas de intervenção no âmbito da educação moral. O objetivo deste artigo é apresentar uma breve visão sobre algumas das principais teorias psicológicas que abordam a questão do desenvolvimento moral, demonstrar algumas propostas de aplicação dessas teorias em programas de intervenção e argumentar que a Educação se apresenta como um espaço privilegiado para o desenvolvimento desse tipo de atividade, que não tem sido devidamente aproveitado no Brasil.

Palavras-chave: moralidade, Psicologia, Educação.

Abstract: In Psychology, the branch of studies about moral development, from a psychogenetic perspective, began with the 1932 book Moral Judgment of the Child. In this book, Jean Piaget refers to a set of experiments demonstrating that morality and acquisitions in the cognition and affective field are related. Nowadays, this field of studies has grown constantly and produced new theories and intervention accounts in the scope of moral education. The objective of this paper is to present a brief overview of the main psychological theories that deal with moral development, demonstrating some interventions and arguing that education is a privileged space for the development of social moral awareness which has not been duly used to advantage in Brazil.

Key words: morality, Psychology, Education. 
Através da aplicação de dilemas morais simples, Piaget investigava as concepções que crianças de diferentes idades possuíam sobre as regras dos jogos, a mentira, o roubo, a justiça, entre outras.

\section{Estudos sobre o desenvolvimento moral}

Em sua única obra destinada à investigação da moralidade, Piaget (1932/1994) apresenta uma série de experimentos que demonstram que o raciocínio moral se transforma e se desenvolve ao longo da infância e da adolescência. Através da aplicação de dilemas morais simples, Piaget investigava as concepções que crianças de diferentes idades possuíam sobre as regras dos jogos, a mentira, o roubo, a justiça, entre outras. Outra estratégia utilizada em suas investigações era pedir para que crianças brincassem com ele, ensinando-o como se comportar diante das regras de alguns jogos, como o pique e o jogo de bolinhas de gude. Piaget fingia não conhecer as regras que regulamentam as brincadeiras infantis para poder questionar as crianças à medida que o jogo prosseguia.

De maneira geral, ele observou que crianças muito novas se comportam de maneira heterônoma diante de questões morais, e acreditava que o respeito unilateral pelas regras estabelecidas por figuras de autoridade é a essência da moralidade. Nesse sentido, crianças por volta dos cinco anos ainda não são capazes de refletir, de maneira autônoma, sobre questões morais, de questionar as convenções socialmente estabelecidas e de construir uma consciência moral independente dos adultos, até que fatores de ordem cognitiva, afetiva e social interajam adequadamente. Entre esses fatores, por exemplo, estariam a diminuição do egocentrismo infantil, a descentração cognitiva e o estabelecimento de relações sociais, nas quais predominam a cooperação e o respeito mútuo. A partir da interação desses e de outros fatores, a criança passa a reconhecer-se como igual diante das outras pessoas, a conceber que as noções morais dependem do estabelecimento de acordos sociais que buscam privilegiar o grupo como um todo e a ter uma consciência moral verdadeiramente autônoma.

Apesar de considerar que a moralidade tenda a desenvolver-se paralelamente à cognição e à afetividade, Piaget (1932/1994) sustenta que não se poderia falar de estágios de desenvolvimento moral propriamente ditos, uma vez que existem variações muito grandes entre as dimensões da moral e entre os valores de diferentes culturas, sendo que, em alguns aspectos, os julgamentos heterônomos tendem a prevalecer, mesmo em sujeitos adultos. Tal fato levou-o a concluir que o mais correto seria falar sobre as diferentes fases de heteronomia e autonomia ao longo da vida e considerar os diferentes contextos nos quais a investigação é realizada.

Piaget (1932/1994) rejeitou perspectivas que propagavam que os valores morais são diretamente introjetados pelas pessoas, e que o papel dos pais e professores deve ser o de ensinar às crianças noções como certo e errado, justo e injusto através de métodos baseados unicamente na coerção, imposição de normas e valores ou utilização de reforços e punições. Ele concebia que as interações sociais têm um papel muito importante para o desenvolvimento da consciência moral autônoma, por oferecer oportunidades para que os sujeitos se descentrem cognitivamente e sejam capazes de enxergar a realidade a partir dos pontos de vista de outras pessoas. Nesse sentido, as interações sociais são essenciais para o desenvolvimento moral, desde que as partes envolvidas sejam tratadas igualitariamente, que se reconheçam como dignas de serem respeitadas e se sintam comprometidas com o respeito às opiniões e valores dos outros.

Os princípios das suas teorias foram investigados e desenvolvidos ao longo dos anos, e deram origens a outras que compartilham a perspectiva psicogenética daquele autor. Uma dessas teorias é a mundialmente conhecida teoria dos estágios morais, do psicólogo americano Lawrence Kohlberg. Diferentemente de Piaget, Kohlberg (1964;1976;1992); acredita que o desenvolvimento da moralidade se dê através de estágios sequenciais hierarquicamente organizados. Além disso, esse autor critica Piaget ao afirmar que as questões propostas pelo psicólogo suíço eram passíveis de revelar mais 
o conteúdo do pensamento do que a estrutura de raciocínio das crianças, o que teria levado Piaget a não identificar estágios de desenvolvimento moral altamente delimitados.

Para Kohlberg (1964;1976; 1992); assim como para Piaget $(1932,1994)$, o desenvolvimento da moralidade está ligado, sobretudo, ao desenvolvimento cognitivo e afetivo e às interações sociais estabelecidas ao longo da vida. Utilizando-se de um instrumento denominado Moral Judgment Interview (MJI), que se constitui de uma série de dilemas morais hipotéticos, Kohlberg construiu uma tipologia na qual se organizam três grandes níveis, compostos, cada um, por dois estágios.

O primeiro nível seria o pré-convencional (estágios 1 e 2), durante o qual predominam noções hedonistas e egoístas, nas quais se busca assegurar apenas os interesses pessoais; o segundo nível é o convencional (estágios 3 e 4), em que as noções morais se vinculam ao cumprimento das convenções sociais, para que o sujeito seja aceito e bem-visto pelos outros; por fim, o terceiro nível é o pós-convencional (estágios 5 e 6), no qual prevalece o respeito pelas instituições sociais e pelos direitos humanos. Segundo os dados obtidos por Kohlberg e seus colaboradores, ao longo dos anos, uma parcela muito pequena da população estadunidense chega a atingir o $5^{\circ}$ estágio de desenvolvimento moral, e apenas algumas figuras históricas, como Gandhi, Madre Tereza e Luther King, teriam alcançado o $6^{\circ}$ estágio.

Kohlberg (1964 apud Hoffman, 1976, 1992) destaca que um fator primordial para a construção da noção de justiça - que é central na sua teoria - seria as interações nas quais existem oportunidades de role-taking e durante as quais os sujeitos interagem e tomam a perspectiva de outras pessoas, imaginando o que elas pensam ou sentem. A idéia por trás desse pressuposto baseia-se na concepção piagetiana de que o desequilíbrio socio-cognitivo provocado por processos de tomada de perspectiva obriga os indivíduos a vivenciarem conflitos capazes de motivá-los a buscar níveis mais elevados de desenvolvimento e estados de equilíbrio cada vez mais estáveis. Nesse sentido, à medida que o sujeito confronta seu ponto de vista com o de outras pessoas, vê-se obrigado a refletir sobre suas próprias idéias e a buscar o refinamento ou o melhoramento das mesmas, através da construção de argumentos mais sólidos e complexos, o que transforma um processo cognitivo em uma atividade de ordem metacognitiva.

Os dados de pesquisas coletados ao longo dos anos, bem como as reflexões teóricas produzidas a partir dos trabalhos de Piaget $(1932,1994)$ e Kohlberg (1964 apud Hoffman, 1976, 1992), deram subsídios para que Blatt, em 1975, juntamente ao próprio Kohlberg, elaborasse um programa de intervenção voltado para a promoção do desenvolvimento moral. Esses pesquisadores demonstraram ser possível fazer os sujeitos evoluírem um ou dois estágios morais através da promoção de debates coordenados, nos quais estejam envolvidos temas morais.

Em linhas gerais, a proposta desse programa é organizar grupos formados por sujeitos de diferentes níveis de desenvolvimento e, estimulando-se o respeito entre os membros do grupo, fazer com que haja confronto de argumentos, promoção de conflitos sociocognitivos e oportunidade de tomadas de perspectivas. Segundo Biaggio (1997), a técnica de Blatt e Kohlberg não busca promover a educação moral pelo relativismo ou pela doutrinação, mas pelo conflito cognitivo produzido nos debates, que possibilita ao professor/ orientador criticar as respostas morais de níveis inferiores sem ser desrespeitoso para com as opiniões dos alunos e sem predeterminar quais sejam as respostas "corretas".

Com base na pesquisa de Blatt e Kohlberg (1975), Kohlberg e seus colaboradores elaboraram e implantaram programas educacionais voltados para o desenvolvimento 
da autonomia moral de estudantes e para a criação de ambientes democráticos em escolas públicas dos Estados Unidos (Kohlberg, Power, Higgins, 1989). Dentre esses trabalhos, destacam-se as escolas secundárias alternativas Cluster (Massachusetts) e a Escola Scardale (Nova York). Nestas, Kohlberg e seus colaboradores buscaram criar ambientes democráticos nos quais alunos e professores tinham direito de opinar igualitariamente e se reuniam em pequenos e grandes grupos (através de uma espécie de assembléia geral) para discutir questões ligadas às normas escolares, atitudes individuais ou grupais, punições, etc, e chegar a decisões coletivas que refletissem a vontade da maioria dos membros da "comunidade". De acordo com Biaggio (1997), alguns estudos demonstraram que o trabalho de Kohlberg foi efetivo para promover avanços na atmosfera moral das escolas durante os quatro primeiros anos de funcionamento do programa.

No Brasil, o trabalho de Dias (1999) demonstra uma aplicação eficaz da técnica de discussão de Blatt e Kohlberg (1975) para promover avanços no julgamento moral. Utilizando-se de um delineamento experimental, essa autora organizou dois grupos (experimental e controle) de adolescentes com diferentes níveis de julgamento moral e avaliou-os em um pré-teste através do Defining Issues Test. Durante quatro meses, os participantes do grupo experimental participaram de sessões de discussão sobre dilemas morais, cujos temas eles mesmo haviam escolhido previamente, enquanto o grupo de controle manteve as atividades escolares rotineiras. Nos resultados do pósteste, Dias observou que, no grupo experimental, o número de participantes que avançou foi significativamente superior ao número de participantes que regrediu nos estágios kohlbergianos de julgamento moral, enquanto, no grupo controle, não houve diferenças entre o número de participantes que avançaram e os que regrediram. Além disso, no grupo experimental, a média dos escores de avanço foi superior à média dos escores de regressão, ao passo que, no grupo controle, não houve diferenças significativas entre essas duas médias.

Outro exemplo interessante de aplicação da técnica supracitada pode ser observado no estudo de Biaggio e col. (1999), que demonstrou que o método desenvolvido por Blatt e Kohlberg também pode ser utilizado para promover avanços nos níveis de maturidade de outros tipos de julgamentos. Nesse estudo, os pesquisadores trabalharam com um grupo de dezesseis adolescentes, durante um semestre letivo, utilizando dilemas com assuntos ligados à ecologia. Nos resultados, observou-se que apenas os adolescentes que participaram efetivamente das discussões haviam aumentado significativamente seus escores de maturidade nos julgamentos relacionados às atitudes ambientais favoráveis, o que indica a importância de aspectos motivacionais para eficácia da técnica de discussão.

Seguindo uma linha de raciocínio semelhante à dos trabalhos anteriores, Covell e Howe (2001) desenvolveram um currículo voltado para o aprendizado sobre os direitos da criança, que foi testado em escolas canadenses, paralelamente ao currículo regular. Para tanto, foram feitas atividades de role-play, discussões, debates sobre direitos e responsabilidades e o desenvolvimento de projetos comunitários. Covell e Howe observaram que, após seis meses de intervenção, as crianças e adolescentes que tomaram parte do programa demonstraram maiores níveis de auto-estima, preocupação com os direitos dos outros e de conhecimento sobre os direitos individuais e coletivos do que outros que não haviam participado do programa.

Os resultados dos estudos descritos anteriormente corroboram o pressuposto piagetiano de que os conflitos cognitivos originados nas interações sociais têm potencial para promover avanços de desenvolvimento, além de demonstrar que a técnica de Blatt e Kohlberg é eficaz em fomentar a evolução nos níveis de julgamento sócio-moral. Além disso, os trabalhos de Biaggio (1997), Biaggio e col. 
(1999) e Dias (1999) sugerem que intervenções dessa natureza podem ser prontamente adaptadas ao contexto educacional brasileiro, desde que existam algumas condições como, por exemplo, envolvimento e capacitação dos professores, organização de espaços (físicos e temporais) adequados, motivação dos alunos, integração do programa ao currículo regular e, acima de tudo, a criação de um clima democrático no qual prevaleça o respeito mútuo entre os membros da comunidade escolar.

A importância dos trabalhos de Piaget e Kohlberg para o desenvolvimento do campo de estudos sobre a moralidade, e para a Psicologia como um todo, é incontestável. Mais especificamente, destaca-se que, a partir da perspectiva psicogenética desses autores, a moralidade passou a ser vista como uma dimensão que evolui sob influência das interações sociais e do desenvolvimento cognitivo-afetivo, e não pode, portanto, ser diretamente ensinada tal como os conteúdos curriculares tradicionais da escola. Apesar dessa importância, alguns teóricos têm criticado esses autores ao afirmar que o estudo da moralidade, a partir das perspectivas piagetiana e kohlbergiana, enfatiza, sobremaneira, fatores de ordem cognitiva e desconsidera a importância que a vida afetiva tem para a moralidade.

No entanto, é preciso lembrar que, na teoria de Piaget (1962; 1932,1994; 2001; 1964/ 2005), cognição e afetividade apresentam-se como aspectos indissociáveis do funcionamento mental e que, nesse sentido, não se pode falar de condutas que representam aspectos de apenas uma dessas dimensões. Kohlberg (1992), por sua vez, afirma que uma interpretação errônea de sua teoria e da teoria de Piaget levou algumas pessoas a acreditarem que o desenvolvimento cognitivo determina o desenvolvimento da afetividade. Segundo Kohlberg, o que ele e Piaget propõem é que afetividade e cognição possuem uma base estrutural comum e paralela, e que os julgamentos morais não são puramente cognitivos, mas possuem componentes afetivos e motivacionais.
Apesar de não ser procedente uma crítica levantada sobre um possível viés cognitivista das teorias piagetiana e kohlbergiana, faz-se necessário salientar que, mesmo esses autores tendo considerado que a afetividade tem um papel importante na construção da moralidade, nem um nem outro estudaram com profundidade qual seria esse papel e quais processos psicológicos estariam envolvidos na relação entre cognição, afetividade e moralidade. Com base nessa lacuna empíricoteórica e partindo do pressuposto de que a afetividade, tanto quanto a cognição, é determinante para o desenvolvimento moral, outros autores têm construído teorias sobre a moralidade cuja orientação epistemológica diverge daquelas adotadas por Piaget e Kohlberg. Um desses autores é Martin L. Hoffman.

Na ciência psicológica, a relação entre afetividade e cognição já havia sido amplamente discutida por grandes autores como Carl Rogers, Gordon Alport e Sigmund Freud, mas foi só com os trabalhos de Hoffman que a vida afetiva passou a ser investigada a partir de uma perspectiva desenvolvimentista e ganhou destaque fora do contexto clínico. Na teoria de Hoffman $(1987,1991)$, destaca-se o impacto que o desenvolvimento da empatia tem sobre o julgamento e comportamento morais. Para esse autor, a empatia diz respeito a uma experiência vicária, na qual um sujeito vivencia uma resposta afetiva que é mais adequada a uma outra pessoa do que a ela mesma. Essa resposta seria produzida, sobretudo, em momentos nos quais o sujeito percebe que a outra pessoa vivencia sensações negativas, dolorosas ou está em situação de perigo potencial, o que desperta estados afetivos semelhantes no próprio observador.

Nesse sentido, e diferentemente de outros autores do campo da Psicologia da personalidade, para Hoffman (1987; 1991), a empatia não diz respeito a um encontro exato de emoções, porque as pessoas são incapazes de sentir exatamente o que os outros sentem. Ao invés disso, ele sugere que, por meio das
Na ciência psicológica, a relação entre afetividade e cognição já havia sido amplamente discutida por grandes autores como Carl Rogers, Gordon Alporte Sigmund Freud, mas foi só com os trabalhos de Hoffman que a vida afetiva passou a ser investigada a partir de uma perspectiva desenvolvimentista e ganhou destaque fora do contexto clínico. 
No que diz respeito especificamente à compaixão - que é um dos componentes do sentimento de simpatia-, Hoffman (1987; 1989a; 1989b;

1991) argumenta que questões afetivas

influenciam

fortemente a elaboração dos julgamentos morais e o engajamento em ações prósociais. representações mentais que as pessoas constroem umas sobre as outras e das pistas situacionais que se fazem mais relevantes no momento em que ocorrem as interações sociais, os seres humanos são capazes de vivenciar, vicariamente, diferentes tipos de afetos empáticos. Entre esses afetos, destacamse o sentimento de injustiça, o ódio e a simpatia.

Apesar de julgar que a empatia seja elemento fundamental para a constituição da moralidade, Hoffman (1987; 1991) também considera a importância que fatores cognitivos têm para o desenvolvimento moral. Para esse autor, com a evolução nas capacidades de tomada de perspectiva e de elaboração de representações mentais, os indivíduos passam a poder desenvolver a empatia com pessoas que estão distantes espacialmente e/ou temporalmente, aplicando a elas os mesmos julgamentos morais aplicados a pessoas que estão mais próximas. Por meio dessa propriedade é que, por exemplo, algumas pessoas são capazes de sentir compaixão pelas famílias das vítimas do furacão que devastou, há algum tempo, a cidade de Nova Orleans, nos Estados Unidos, mesmo que essas pessoas não estejam lá.

No que diz respeito especificamente à compaixão - que é um dos componentes do sentimento de simpatia -, Hoffman (1987; $1989^{\text {a }}$; 1989 $\left.{ }^{\text {b; }} 1991\right)$ argumenta que questões afetivas influenciam fortemente a elaboração dos julgamentos morais e o engajamento em ações pró-sociais. Assim, a simpatia, além de produzir um sentimento de angústia ou preocupação, também possui um componente motivacional que impele o indivíduo a buscar uma forma de aliviar o sofrimento, a injustiça ou o revés do próximo. A simpatia seria, então, a explicação para o fato de algumas pessoas se engajarem em ações sociais que buscam promover maior qualidade de vida para indivíduos marginalizados, excluídos ou que sofrem algum tipo de injustiça, mesmo que, para isso, elas tenham que sacrificar algumas vontades pessoais.
Segundo Hoffman (1987; 1991), além dessa propriedade motivacional, a empatia seria muito importante para a internalização e escolha de princípios morais em situações nas quais diferentes cursos de ação se tornam possíveis e que dilemas morais se estabelecem. Essa importância se revela na medida em que a associação entre um princípio moral e um afeto empático/simpático cria uma representação mental afetivamente carregada, chamada de hot-cognition. Essa representação é fundamental para a promoção do desenvolvimento moral, pois, em uma situação na qual o sujeito tenha que escolher entre um ou mais princípios disponíveis, ou tenha que internalizar um novo princípio, o processo passa a ser mediado por um componente afetivo, com características claramente altruísticas. Além disso, as hotcognitions teriam a capacidade de dirigir o comportamento do sujeito em situações futuras, o que possibilita a aplicação imparcial de princípios morais a contextos diferentes daqueles nos quais as hot-cognitions foram originalmente constituídas.

Partindo de pressupostos semelhantes àqueles propostos por Hoffman (1987; 1991), uma série de autores (Kristjaânsson, 2004) tem afirmado a importância de que se investiguem, com mais profundidade, as relações entre aspectos afetivos, cognitivos e a moralidade. No Brasil, citam-se, como exemplos, os trabalhos de Ceconello e Koller (2000) e Araújo (2000) e Lima (2004). Além disso, tem-se discutido (Ruiz, Vallejos, 1999; Araújo, 2000; Verducci, 2000) cada vez mais a importância de que a educação moral passe a ser guiada por parâmetros que não enfatizem apenas um modelo puramente racional/cognitivista, mas que se paute na constituição de programas nos quais aspectos afetivos possam ser englobados às propostas de intervenção.

Stephan e Finlay (1999), por exemplo, fazem uma revisão de alguns programas de intervenção cujos objetivos eram promover a autonomia moral e o engajamento em comportamentos pró-sociais, estimulando a capacidade de roletaking e o desenvolvimento de habilidades 
empáticas, através de atividades como discussão sobre dilemas morais, role-plays, debates com a participação de pessoas de diferentes grupos étnico-raciais, etc. Um diferencial desses programas em relação à técnica de Blatt e Kohlberg (1975) é que, em algumas dessas atividades, solicita-se explicitamente que os participantes tentem se colocar no lugar das outras pessoas e a imaginar o que elas estariam pensando ou sentindo. Como Batson e cols. (1995) demonstraram, esse tipo de instrução tem o potencial para estimular componentes cognitivos e afetivos da empatia, passíveis de influenciar o comportamento e o julgamento moral das pessoas. Tal fato pode ser de bastante valia para o campo da educação moral, visto o potencial que esse tipo de técnica pode ter.

\section{Psicologia moral e Educação: espaço de interlocução}

Considerando-se as importantes descobertas empíricas e reflexões teóricas produzidas no campo do desenvolvimento moral ao longo dos anos, uma questão se impõe: como esses dados têm sido transformados em ações voltadas para o desenvolvimento de indivíduos moralmente autônomos e comprometidos com o respeito ao próximo? Na nossa perspectiva, essas ações se apresentam, ainda, de maneira muito tímida, considerando-se a enorme quantidade de dados já produzidos e uma necessidade social cada vez mais forte. Exemplo da existência dessa necessidade é que se fala constantemente sobre uma possível inversão de valores na contemporaneidade. Por conseguinte, pregase que esse processo é responsável por levar as pessoas a não se pronunciar diante de, e até mesmo a concordar com atos que ferem violentamente a dignidade humana. Acessar algum meio de informação e analisar as principais manchetes, conversar com os colegas no trabalho, ou mesmo olhar para fatos do cotidiano com um pouco mais de atenção já é suficiente para que se perceba que realmente existe alguma coisa errada ou "invertida" em nossa sociedade: o mundo vive com medo de ameaças terroristas, as nações promovem guerras por interesses escusos, crescem as desigualdades sociais, a miséria e o sofrimento das pessoas, autoridades utilizam-se do poder para desviar dinheiro de pessoas mais necessitadas, etc.

A partir de uma análise sobre essa realidade e do potencial que o conhecimento tem para promover transformações sociais, uma segunda questão deve ser formulada: é possível utilizar o conhecimento produzido no campo de investigações sobre o desenvolvimento moral para promover ações capazes de transformar a realidade social supracitada? Antes de tudo, é importante salientar que, com tais questionamentos, não estamos tentando encontrar uma "fórmula para salvar a humanidade de si mesma”. A proposta do presente trabalho é muito mais modesta, e sugere apenas que a Educação moral tem muito a contribuir para a construção de uma sociedade mais justa e solidária, na qual os sujeitos são moralmente autônomos e se respeitam mutuamente. Todavia, ressalta-se que essa contribuição deve passar, necessariamente, por uma análise cuidadosa do conhecimento até então produzido em diversas áreas e por uma reflexão acerca da construção de espaços nos quais esses conhecimentos possam ser aplicados de maneira eficaz. A nosso ver, um desses espaços é constituído justamente na interface ocupada pela Psicologia e pela Educação, no âmbito da educação moral.

Não é de hoje que esses dois campos exercem influência um sobre o outro e contribuem para o desenvolvimento científico e social. Apesar das dificuldades em se transformar resultados de pesquisa e conhecimento psicológico em práticas educativas e da ocorrência de algumas distorções desse conhecimento, quando de sua aplicação ao contexto escolar, considera-se que a inter-relação entre Psicologia e Educação tem sido muito produtiva e promissora. Porém, no que diz respeito especificamente à educação moral, julga-se que ainda não há uma verdadeira aproximação entre esses campos. ...é possivel utilizar o conhecimento produzido no campo de investigações sobre o desenvolvimento moral para promover ações capazes de transformar a realidade social supracitada? 
"compreender a cidadania como participação social e política, assim como exercício de direitos e deveres políticos, civis e sociais, adotando, no dia a dia, atitudes de solidariedade, cooperação e repúdio às injustiças, respeitando o outro e exigindo para si o mesmo respeito"

(BRASIL, 1997, p. 09)
Nesse sentido, a Psicologia tem se mostrado muito eficaz em investigar e compreender os processos envolvidos no desenvolvimento sócio-moral, ao mesmo tempo em que caminha muito lentamente quando se pensa na aplicação do conhecimento produzido fora de contextos experimentais. A Educação, por sua vez, trabalha com questões pertinentes para a promoção do desenvolvimento sócio-moral, mas de maneira puramente didática e com ênfase, sobremaneira, apenas nos aspectos cognitivos envolvidos naquele processo. Além disso, em nosso país, a Educação sofre com uma enorme dificuldade de eleger temas prioritários para a formação dos estudantes, pois, de maneira geral, o ingresso na Universidade ou no mercado de trabalho tem se tornado o último e mais importante objetivo do sistema educacional brasileiro.

\section{Os Parâmetros Curriculares Nacionais e o desenvolvimento moral}

No que se refere à questão da educação moral, observa-se que essa temática é abordada pelos Parâmetros Curriculares Nacionais - PCNs, mais especificamente nos trechos em que se discute a questão dos temas transversais e da ética. Segundo tal documento, a Educação deve estar voltada não só para o ensino de conteúdos acadêmicos tradicionais, mas também preocupada com a formação de cidadãos comprometidos com o respeito pelo meio ambiente, a diversidade cultural, a dignidade e o valor da vida humana. Para alcançar essas metas, sugere-se que a discussão sobre temas como saúde, pluralidade cultural, meio ambiente, orientação sexual e a própria ética esteja acoplada ao ensino de disciplinas tradicionalmente trabalhadas nas escolas, como Física, Química, História, etc. Ressalta também que a informação deve ser vista como um dos fatores responsáveis pela formação e transformação de valores e atitudes, mas não como o único, pois os educadores devem considerar também o conhecimento e os valores que as crianças trazem para o ambiente escolar.
O texto dos PCNs destaca que um dos objetivos do ensino fundamental deve ser capacitar os alunos para: "compreender a cidadania como participação social e política, assim como exercício de direitos e deveres políticos, civis e sociais, adotando, no dia a dia, atitudes de solidariedade, cooperação e repúdio às injustiças, respeitando o outro e exigindo para si o mesmo respeito" (BRASIL, 1997, p. 09). Nesse sentido, a educação brasileira deve ser norteada por princípios que assegurem a dignidade da pessoa humana, a igualdade de direitos entre as pessoas, a participação e a co-responsabilidade pela vida social. Como exemplos de práticas escolares nas quais se possa promover a formação de uma consciência cidadã, os PCNs sugerem atividades nas quais os indivíduos possam construir regras de convivência, a utilização de discussões coletivas acerca de situações-problema, com temáticas ligadas ao respeito mútuo e à cooperação e o desenvolvimento de projetos nos quais os estudantes realizem ações voltadas para a promoção da cidadania, entre outras.

A nosso ver, conseguir fazer com que as ações pessoais e institucionais se baseiem nos princípios defendidos pelos PCNs é o objetivo principal desejado por qualquer Estado democrático e meta a ser perseguida por todo programa de intervenção que vise a promover o desenvolvimento sócio-moral. Porém, uma análise superficial do sistema educacional brasileiro já é suficiente para indicar que a proposta mais geral dos Parâmetros Curriculares Nacionais, na maioria dos casos, não vem sendo efetivamente colocada em prática. Os fatores que impedem que o projeto de educação cidadã sugerido pelos PCNs se transforme em ações realmente efetivas têm sido amplamente discutidos e dizem respeito, sobretudo, a questões culturais, econômicas e políticas mais amplas, sobre as quais não se pretende debruçar no presente trabalho. Como já foi dito, o que se pretende, neste artigo, é sugerir a possibilidade de construção de um espaço de diálogo e interlocução entre a Psicologia moral e a Educação, no qual se possa pensar melhor nessas questões e no qual o conhecimento 
possa ser verdadeiramente transformado em ações.

Compartilhando da perspectiva psicogenética de autores como Piaget, Lev Vigotsky e Henri Wallon, considera-se que a escola se constitui em um espaço privilegiado de interação, no qual o desenvolvimento deve ser promovido e amplamente estimulado em todas as suas dimensões. Na escola, os alunos se deparam com a diversidade em suas várias nuances (cultural, social, ideológica, etc) e têm que aprender a respeitar regras e costumes vigentes naquela instituição, ao mesmo tempo em que não perdem sua individualidade. Nesse sentido é que a escola é vista como um local onde se formam conflitos das mais diversas ordens, importantíssimos para a constituição da subjetividade.

De maneira geral, observa-se que existem pressupostos comuns entre as teorias de autores como Piaget e Kohlberg e a proposta defendida pelos Parâmetros Curriculares Nacionais ${ }^{1}$. Considera-se, por exemplo, o destaque que ambos dão às interações sociais e às atividades que promovem desequilíbrios socio-cognitivos com vista à promoção do desenvolvimento moral. Todavia, considera-se que o diálogo entre Psicologia e Educação ainda é insuficiente para que se possa pensar em ações que vão além do paradigma racionalista/ intelectualista e que, ao mesmo tempo, sejam viáveis. Segundo Dias (1999), algumas pesquisas demonstram que, na maior parte das escolas brasileiras, existe uma prevalência de modelos educacionais nos quais predominam a heteronomia moral, a coerção e o respeito unilateral, características essas que representam entraves ao desenvolvimento de uma consciência moral autônoma, tal qual havia sido proposto por Piaget.

Concordamos com Galvão (2004) quando afirma que a Educação não pode ter, como meta máxima, apenas o desenvolvimento intelectual, visto que essa dimensão representa apenas um meio para que se possa chegar ao desenvolvimento da pessoa como um todo.
Nesse sentido, os dados produzidos no campo das investigações psicológicas podem ser de fundamental importância para a construção de novas propostas para a educação moral, nas quais se considere o papel da afetividade para a formação de indivíduos moralmente autônomos e socialmente comprometidos.

Conceber a Educação como um espaço dialógico no qual esses processos sejam vistos a partir de uma perspectiva mais afetiva e repensar a própria noção de moralidade configuram bons pontos de partida. Além disso, redefinir os objetivos da educação moral e da própria Educação como um todo é elemento imprescindível para que a interface entre Psicologia e Educação seja fortalecida.

Transformar teorias (sejam elas científicas, políticas ou de qualquer outro tipo) e resultados de pesquisa em ações capazes de mudar a realidade é um processo difícil e meticuloso para o qual se fazem necessárias clareza dos objetivos, coerência da proposta e responsabilidade na implementação da mesma. Se esses objetivos passam pelo aprendizado meramente didático (ou “frio", como diria Hoffman) de princípios ou padrões ideais de comportamento, e por uma aprendizagem de nível meramente lingüístico, então os modelos propostos para a educação moral atuais dão conta do recado. Contudo, se o objetivo é formar cidadãos que, além de falar sobre princípios morais ideais, sejam verdadeiramente comprometidos com esses princípios e com a construção de uma sociedade mais justa, considera-se que novos modelos devam ser propostos.

O processo de mudança no âmbito da educação moral já foi iniciado em outros países, mas, no Brasil, ele caminha muito lentamente, com enorme distanciamento entre prática e teoria. Considera-se de fundamental importância maior aproximação entre Psicologia e Educação, no sentido de que se possam pensar, conjuntamente, estratégias para aplicação do conhecimento na elaboração de políticas públicas educacionais voltadas para a formação
1 Para uma discussão mais aprofundada sobre esta questão, sugere-se consultar Oliveira (2001). 
2.Por exemplo, no texto dos PCNs afirma-se que a autonomia moral é um estágio de desenvolvimento psicológico atingido pelos indivíduos.

3. Como exemplo, cita-se a proposta do programa LVEP - Living Values Educational Program, a qual vem sendo atualmente trabalhada nos Estados Unidos. Este programa visa, em linhas gerais, capacitar professores para que os mesmos possam contribuir para o processo de internalização de valores morais dos seus alunos. da consciência cidadã. Algumas dessas estratégias podem passar pela criação de ambientes educacionais nos quais os alunos aprendam a opinar e a serem responsáveis pelas suas decisões, nos quais o conhecimento sobre o desenvolvimento sócio-moral e afetivo faça parte da formação dos educadores, onde temas como ética, valores, direitos e justiça possam ser discutidos democraticamente, e nos quais prevaleça o respeito mútuo entre os membros do grupo. Por fim, julga-se que o aperfeiçoamento e a adequação de propostas como as de Blatt e Kohlberg (1975) e aquelas descritas por Stephan e Finlay (1999) sejam muito importantes para a transformação da realidade educacional e social brasileira. Talvez, dessa maneira, o potencial que a Educação tem para transformar a realidade social e para formar indivíduos socialmente responsáveis, solidários e comprometidos com o respeito aos direitos humanos seja plenamente aproveitado.

\section{Considerações finais}

As investigações psicológicas sobre a moralidade e a afetividade evoluíram bastante nas últimas três décadas e produziram um corpo de dados muito significativo para a compreensão dos processos envolvidos na vida em sociedade. Partindo de teorias psicológicas como as de Piaget, Kohlberg e Hoffman, têm-se desenvolvido trabalhos de intervenção que visam a promover o desenvolvimento sócio-moral e afetivo em contextos educacionais. De maneira geral, países como os Estados Unidos têm investido bastante em programas desse tipo e no desenvolvimento de novas tecnologias educacionais.
No caso do Brasil, apesar dos Parâmetros Curriculares Nacionais proporem que o desenvolvimento moral e a formação da consciência cidadã devem ser estimulados nas escolas desde as primeiras séries, não se tem notícia de ações que sejam realmente eficazes para promover tal desenvolvimento.

Considera-se que uma aproximação maior entre a Psicologia e a Educação poderá colaborar muito para a elaboração de ações que transformem a proposta geral dos PCNs em políticas públicas efetivas e práticas educacionais mais sofisticadas, que ousem desafiar a hegemonia do paradigma racionalista/ intelectualista presente em nosso sistema educacional. No âmbito da educação moral, aspectos afetivos devem ser considerados tão importantes quanto aspectos cognitivos, afinal de contas, a moralidade não pode ser ensinada como outro conteúdo qualquer, pelo menos não nos moldes clássicos em que um sujeito ensina e o outro aprende passivamente.

A verdadeira consciência moral autônoma deve ser construída através de interações nas quais prevaleçam o respeito mútuo e a cooperação, e nas quais a afetividade seja vista como um dos fatores responsáveis pela mobilização das ações em nível pessoal e interindividual. Como diria o próprio Piaget (1962, p.3), “... não há atos de inteligência, mesmo de inteligência prática, sem interesse no ponto de partida e regulação afetiva durante todo o processo de uma ação, sem prazer do sucesso ou tristeza no caso do fracasso".

Leonardo Rodrigues Sampaio

Mestre em Psicologia Cognitiva pela Universidade Federal de Pernambuco.

Universidade Federal Do Vale Do São Francisco - UNIVASF. Campus Petrolina. Colegiado de Psicologia. Av. Deputado Manoel Novaes s/n. Bairro Maria Auxiliadora. CEP: 56302-970. Petrolina PE. Fone: (87) 3863-9046.

E-mail: leorsampaio@yahoo.com.br

Recebido 15/08/06 Reformulado 07/02/07 Aprovado 08/02/07 
ARAÚJO, V. A. A. Cognição, afetividade e moralidade. Educação e Pesquisa, São Paulo, v. 26,n. 2, pp.137153, 2000

BATSON, C. D.; KLEIN, T. R.; HIGHBERGER, L.; SHAW, L. L. Immorality from empathy-induced altruism: when compassion and justice conflict. Journal of Personality and Social Psychology, Washington, v. 68, n. 6, pp.1042-1054, 1995.

BIAGGIO, A.M.B. Kohlberg e a "Comunidade Justa": promovendo o senso ético e a cidadania na escola. Psicologia, Reflexão e Crítica, Porto Alegre, v. 10, n. 1, pp.47-69, 1997.

BIAGGIO, A. M. B., VARGAS, G. A. O., MONTEIRO, J. K., SOUZA, L. K., TESCHE, S. L. Promoção de atitudes morais favoráveis através de dilemas ecológicos. Estudos de Psicologia, Natal, v. 4, n. 2, pp. 221-238, 1999.

BLATT, M. M. e KOHLBERG, L. The effects of classroom moral discussion upon children's level of moral judgment. Journal of Moral Education, Colchester, $n$. 4, pp.129-161,1975.

BRASIL. Parâmetros Curriculares Nacionais: Apresentação dos Temas Transversais: Ética. V. 08. Brasília: MEC/SEF, 1997.

COVELL, K. e HOWE, R. B. Moral Education through the 3 Rs: rights, respect and responsibility. Journal of Moral Education, Colchester, v.30, n. 1, pp.29-41, 2001.

CECCONELLO, A. M; KOLLER, S. H. Competência social e empatia: um estudo sobre resiliência com crianças em situação de pobreza. Estudos de Psicologia, Natal, v.5, n. 1, pp.71-93, 2000.

DIAS, A. A. Educação moral para a autonomia. Psicologia, Reflexão e Crítica, Porto Alegre, v.12, n. 2, pp.459-478, 1999.

GALVÃO, I. Henri Wallon: uma Concepção Dialética do Desenvolvimento Infantil. $13^{\mathrm{a}}$ ed. Petrópolis: Vozes, 2004.

HOFFMAN, M. L. The Contribution of Empathy to Justice and Moral Judgment. In: Eisenberg, N. e Strayer (orgs.). Empathy and its Development. New York: Cambridge University Press, 1987, pp.215-240.

Empathy and Prosocial Activism. In: Eisenberg, N., Reykowski, J., Staub, E. (orgs.). Social and Moral Values: Individual and Societal Perspectives. Hillsdale, N. J. Erbaum., 1989 ${ }^{\mathrm{a}}$, pp.6585.

Empathy, Role-taking, Guilt and Development of Altruistic Motives. In: Eisenberg, N., Roykowsky, J. Staub, E. (orgs.) Social and Moral Values: Individual and Societal Perspectives. New York, Hillsdale, $1989^{\mathrm{b}}$, pp.139-152.
Empathy, Social Cognition and Moral Action. In: Kurtines, W. M. e Gewirtz, J. L. (orgs.). Handbook of Moral Behavior and Development Vol.1: Theory. New Jersey: LEA, 1991, pp.187-212.

KRISTJAÂNSSON, K. Empathy, sympathy, justice and the child. Journal of Moral Education, Colchester, v.33, n. 3, pp.291-305, 2004.

KOHLBERG, L. Development of Moral Character and Moral Ideology. In: Hoffman, M. L. e Hoffman, L. W. Review of Child Development Research. Vol. 1. New York: Russel Sage Foundation, 1964, pp.212-321.

Moral Stages and Moralization: the Cognitive-developmental Approach. In: Lickona, T. Moral Development and Behavior: Theory, Research and Social Issues. New York: Holt, Rinehart and Winston, 1976, pp. 76-90.

Psicologia del Desarrollo Moral. $2^{\text {a }}$ vol. Bilbao: Editorial Disclée de Brower S.A, 1992.

KOHLBERG, L.; POWER, F. C.; HIGGINS, A. La Educación Moral según Lawrence Kohlberg. Barcelona: Gedisa Editorial, 1989.

LIMA, V. A. De Piaget a Gilligan: retrospectiva do desenvolvimento moral em Psicologia - um caminho para o estudo das virtudes. Psicologia: Ciência e Profissão, Brasília, v.24, n.3, pp.12-33, 2004.

OLIVEIRA, R. J. Ética na escola: (re) acendendo uma polêmica. Educação \& Sociedade, n. 76, pp.212-231, 2001.

PIAGET, J. The relation of affectivity to intelligence in the mental development of the child. Bulletin of the Menninger Clinic, London, v.26, $\mathrm{n}^{\circ}$ 3, pp.129-137, 1962.

PIAGET, J. PIAGET, J. O Juízo Moral na Criança.São Paulo: Summus Editora, 1932, 1994, deve ser PIAGET, J. (1932) O Juízo Moral na Criança. São Paulo: Summus Editora, 1994

Aique, 2001.

Inteligencia y Afectividad. Buenos Aires:

(1964). Seis Estudos de Psicologia. 24 ed. Rio de Janeiro: Forense Universitária, 2005.

RUIZ, P. O; VALLEJOS, R. M. The role of compassion in Moral Education. Journal of Moral Education, Colchester, v.28, $\mathrm{n}^{\circ}$ 1, pp.5-17, 1999.

STEPHAN, W. G e FINLAY, K. The role of empathy in improving intergroup relations. Journal of Social Issues, New York, v.55, n. 4, pp.729-743, 1999.

VERDUCCI, S. A Moral method? Thoughts on cultivating empathy through method acting. Journal of Moral Education, Colchester, v.29, $\mathrm{n}^{\circ}$ 1, pp.87-99, 2000.

\section{Referências}

